\title{
Defensive Responses to Early Memories with Peers: a Possible Pathway to Disordered Eating
}

Cláudia Ferreira, Joana Marta-Simões and Inês A. Trindade

Universidade de Coimbra (Portugal)

Correspondence concerning this article should be addressed to:

Joana Marta-Simões, University of Coimbra - Faculty of Psychology and Educational Sciences, Rua do Colégio Novo, Apartado 6153, 3001-802. Coimbra (Portugal).

Phone: +351-239851450; +351-239851462

E-mail: mjoana.gms@gmail.com 


\section{Abstract}

Childhood and early adolescence experiences, specifically those that provide an adulthood enriched with warm and safe memories, are consistently stated in literature as powerful emotional regulators. In contrast, individuals who scarcely recall positive experiences may begin to believe that others see the self as inferior, inadequate and unattractive. In order to cope with a perceived loss of social desirability and achieve other's acceptance, individuals may become submissive, and women, particularly, may resort to the presentation of a perfect body image. Both mechanisms are defensive responses suggested to be associated with mental health difficulties, particularly disordered eating behaviors. The present study aimed at exploring the association between early memories of warmth and safeness with peers and eating psychopathology. Also, a path analysis was conducted to investigate the mediator role of submissiveness and perfectionistic self-presentation focused on body image on this association, in a sample of 342 female students. Results revealed that the absence of early positive memories with peers holds a significant effect over eating psychopathology's severity, and also that this effect is mediated through submissiveness and body image-related perfectionistic self-presentation. This model accounted for $13 \%$, $19 \%$ and $51 \%$ of submissiveness, perfectionistic self-presentation of body image and eating psychopathology's variances, respectively, and showed excellent model fit.

These findings seem to suggest the relevance of targeting maladaptive defensive responses on mental health promotion programs among female students.

Keywords: defensive responses, early memories, eating disorders.

Early experiences of warmth and safeness have been referred in literature as crucial to the subsequent individual's emotional and social development (Gilbert, 2005; Richter, Gilbert, \& McEwan, 2009). In fact, these experiences seem to play a key role on emotional regulation, due to its association with self-reassurance and self-soothing abilities, useful when facing setbacks or failures (Baldwin \& Dandeneau, 2005; Gilbert, Baldwin, Irons, Baccus, \& Palmer, 2006; Richter et al., 2009). In contrast, research suggests that early adverse experiences with family and peers (e.g., abuse, rejection, 
neglect, criticism and bullying) may trigger defeat and threat-related emotional states (e.g., Cunha, Matos, Faria, \& Zagalo, 2012), and motivate defensive responses with deleterious consequences on one's experience of the self and of others (e.g., Gilbert, 2003). In fact, the exposure to negative early experiences is associated with higher vulnerability to psychopathology and maladjustment in adulthood (Gilbert et al., 2006; Irons, Gilbert, Baldwin, Baccus, \& Palmer, 2006). For instance, early shame experiences, particularly the ones inflicted by peers, have been associated with eating psychopathology's severity (Matos, Ferreira, Duarte, \& Pinto-Gouveia, 2015; Sweetingham, \& Waller, 2008).

Submissive behavior is a form of defensive behavior enacted when individuals are under some kind of social threat from a more powerful other (Gilbert, 1989; Gilbert \& Allan, 1994). In fact, by signaling one's intention of giving up on the competition with others and avoiding conflict (Allan \& Gilbert, 1995, 1997; Gilbert \& Allan, 1998), submissive behavior may serve the purpose of assuring acceptance and the sense of belonging to a social group (Gilbert, 1992, 1997, 2000). Although voluntary submissiveness (e.g. supporting others ideas) is not usually associated with psychological distress, involuntary submissive behaviors (e.g., complying with requests to appease others, appearing friendly, both against one's own will; Allan \& Gilbert, 1997) are actually associated with several psychopathological conditions (Gilbert, 1992; Sloman, Price, Gilbert, \& Gardner, 1994). To this concern, a particular investment has been made in the study of the link between involuntary submissiveness and eating psychopathology, showing an association between submissive behaviors, such as helplessness, avoidance and perceived lack of control, and disordered eating behaviors and attitudes (Katzman, 1985; Troop \& Treasure, 1997). Specifically, Connan and colleagues (Connan, Troop, Landau, Campbell, \& Treasure, 2007) corroborated a previous study (Troop, Allan, Treasure, \& Katzman, 2003) by showing that individuals with eating disorders report themselves as being more submissive than non-eatingdisordered women, and extended previous results, showing that even when recovered, women with a history of eating disorders appeared to be more submissive than nonclinical participants.

Also in line with the primary necessity of attaining other's positive attention and approval (Gilbert, Price, \& Allan, 1995), individuals may also engage in strategies of minimization of the public display or disclosure of mistakes and of active promotion of perfect qualities (Hewitt et al., 2003). These strategies, conceptualized as perfectionistic 
self-presentation, entail a maladaptive interpersonal style associated with several forms of psychological distress (Hewitt et al., 2003) and clinical conditions, particularly eating psychopathology (e.g., Cockell et al., 2002; Hewitt, Flett, \& Ediger, 1996).

Given the historical relevance of the female body shape as a central domain in self and social evaluations (Gatward, 2007), the majority of women tend to invest in this dimension with the purpose of promoting attractiveness in the minds of others (Gilbert et al., 1995). However, such investment may demand extreme self-monitoring patterns and control over one's body weight, shape, and eating behaviors, in order to reach the "perfect" physical appearance (Ferreira, Trindade, \& Ornelas, 2015). The need to present one's physical appearance in a perfectionistic way, conceptualized as body image-related perfectionistic self-presentation, has been associated with proneness to eating disorders, particularly to the increase of body dissatisfaction and drive for thinness (Ferreira, Duarte, Pinto-Gouveia, \& Lopes, 2015, manuscript submitted for publication; Ferreira et al., 2015).

The main goal of the present study was to test a novel and integrative model, which explores the impact and role of early memories of warmth and safeness with peers, submissive behaviors, and perfectionistic self-presentation focused on body image on eating psychopathology. It was hypothesized that the impact of the absence of such positive memories on the engagement in disordered eating attitudes and behaviors, is mediated through defensive responses, such as submissiveness and perfectionistic self-presentation strategies.

\section{Method}

\section{Participants}

The sample comprised 342 female students, with age ranging from 18 to 30 years old $(M=20.94 ; S D=2.22)$, and a mean of $13.87(S D=1.59)$ of years of education.

\section{Measures}

Demographic Data.

Participants were required to report their age, completed education years, and also their current weight and height. 


\section{Body Mass Index (BMI).}

The Body Mass Index was calculated dividing self-reported current weight, in Kilograms, by the height squared, in Meters $\left(\mathrm{kg} / \mathrm{m}^{2}\right)$

Early Memories of Warmth and Safeness Scale - Peer version (EMWSS-P; Ferreira et al., 2016, manuscript submitted for publication)

EMWSS-P is a self-report instrument adapted from the Early Memories of Warmth and Safeness Scale (EMWSS; Richter et al., 2009), designed to specifically assess early positive memories of warmth and affect with peers. It consists of 12 items, such as "I felt understood by my peers/friends" or "I felt safe and secure with my peers/friends", rated on a five-point Likert scale that ranges from 0 ("No, never") to 4 ("Yes, most of the time"). The validation studies of this scale showed that EMWSS-P is a robust and reliable measure, with good psychometric qualities, particularly a Cronbach's Alpha of .97 and good convergent and discriminant validity.

Submissive Behaviour Scale (SBS, Allan \& Gilbert, 1997; Freitas, 2011).

The SBS assesses the frequency of submissive behaviors within social situations. The self-report scale consists of 16 items such as "I agree that I am wrong even though I know I'm not" or "I avoid direct eye contact", rated in a five-point Likert scale, ranging from 0 ("never") to 4 ("always"). The original study reported a good internal consistency ( $\alpha=.82, \alpha=.85$, for clinical and student samples, respectively), and well as the Portuguese validation study (Cronbach's alpha values of .85, and .90, for clinical and non-clinical samples, respectively).

Perfectionistic Self Presentation Scale - Body Image (PSPS-BI; Ferreira, et al., 2015).

The PSPS-BI is a self-report scale designed to assess the need to present a perfect body image to others, by displaying a flawless physical appearance and by occulting perceived body imperfections. It consists of 19 items, such as "It is important to have an attractive physical appearance" or "I strive so that others do not become aware of certain characteristics of my body", rated in a seven-point Likert scale, ranging from 1 ("Completely disagree") to 7 ("Completely agree"). This scale showed good psychometric characteristics in the original study, with a high internal consistency $(\alpha=$ $.88)$. 
Eating Disorder Examination Questionnaire (EDE-Q; Fairburn \& Beglin, 1994; Machado et al., 2014).

The EDE-Q is a self-report measure that evaluates nuclear attitudes and behaviors associated with eating disorders, accessing the presence and severity of eating psychopathology. It comprises four subscales: (1) restraint (RESTR), e.g. "Have you tried to exclude from your diet any foods that you like in order to influence your shape or weight?"; (2) eating concern (EAT.C), e.g. "Have you had a definite fear of losing control over eating?"; (3) shape concern (SHA.C), e.g. "How dissatisfied have you been with your shape?"; and (4) weight concern (WEI.C), e.g. "How dissatisfied have you been with your weight?". The items (36) comprising these subscales are rated for the frequency of occurrence and for the severity of key attitudinal and behavioral features of eating psychopathology, within a 28-day time frame. The global EDE-Q score (EDEQ) can also be obtained by calculating the mean of the four subscale scores. The scale showed good psychometric properties $(\alpha=.94$, for both the original and the Portuguese versions).

Cronbach's alphas of these measures for the current study are reported in table 1.

\section{Procedures}

The present study is part of a wider project about emotional regulation processes and eating behavior in Portuguese students, in which 863 individuals comprising both college students and subjects from the general population participated. All ethical requirements were strictly respected, as the Ethics Committees involved gave their approval, and participants were fully informed about the nature and objectives of the study, the voluntary nature of their participation and the confidentiality of the data, which was exclusively used for research purposes. Participants provided their written informed, and only then a battery of self-report questionnaires was administered and completed for approximately 15 minutes. The student sample was collected directly in higher education institutions, and students from several distinct academic areas (e.g., humanities, social sciences, formal sciences, arts) completed the self-report questionnaires in the presence of one of the researchers, after authorization by the professor in charge. Concerning the general population, a convenience sample was collected on various enterprises and institutions, during a break authorized by the boards. 
According to the purposes of this study, data was cleaned, dismissing male participants, non-current students, and also the cases in which more than $15 \%$ of the responses were missing from a questionnaire.

\section{Data Analysis}

The software IBM SPSS (v.22; SPSS Inc., Chicago, IL) was used to perform data analysis, and path analysis were examined using the software Amos (Analysis of Momentary Structure, v.22, SPSS Inc., Chicago, IL).

Descriptive statistics (means and standard deviations) were used to explore the characteristics of the sample in the study variables.

Product-moment Pearson correlation analysis were conducted to explore the association between early memories of warmth and safeness with peers (EMWSS-P), body mass index (BMI), submissive behaviors (SBS), body image-related perfectionistic self-presentation (PSPS-BI) and the severity of eating psychopathology (EDE-Q subscales and global score).

Finally, path analysis was conducted to explore presumed structural relations (direct and indirect effects) among the variables in the proposed theoretical model and, specifically, examine whether EMWSS-P would predict EDE-Q, when mediated by SBS and PSPS-BI, after controlling for BMI (Figure 1). Therefore, EMWSS-P and BMI were considered to be exogenous variables, SBS and PSPS-BI were hypothesized as the endogenous mediator variables, and EDE-Q was entered as an endogenous variable.

The model's path coefficients significances were tested, and fit statistic were computed, using the Maximum Likelihood estimation method, with 95\% confidence interval. The significance of the direct, indirect and total effects was assessed by ChiSquare tests. Also, the Bootstrap resampling method was used to test the significance of the mediational paths, using 2000 Bootstrap samples and 95\% confidence intervals (Kline, 2005). Several goodness-of-fit measures were used to assess the credibility of the overall model, such as Chi-Square $\left(\chi^{2}\right)$, Normed Chi-Square $\left(\chi^{2} / d f\right)$, Tucker Lewis Index (TLI), Comparative Fit Index (CFI), and the Root-Mean Square Error of Approximation (RMSEA) with 95\% confidence interval.

\section{Results}

Descriptives 
Means and standard deviations for all studied variables are presented in Table 1.

\section{Correlations}

Results showed that BMI did not correlate significantly with early memories of warmth and safeness with peers (EMWSS-P), and with submissive behaviors (SBS). However, BMI presented a significant positive, albeit weak, association with perfectionistic self-presentation - body-image (PSPS-BI). Also, a positive association was found between BMI and all the indicators of eating psychopathology.

EMWSS-P showed significant negative correlations with all studied variables. In contrast, SBS and PSPS-BI were found to be positively linked to higher levels of EDEQ (subscales and global score). As expected, strong positive associations were found among all subscales and global score of EDE-Q.

Table 1.

Cronbach's alphas $(\alpha)$, means $(M)$, standard deviations $(S D)$, and intercorrelation scores on self-report measures $(N=356)$

\begin{tabular}{lccccccccccc}
\hline \multicolumn{1}{c}{ Measures } & $\alpha$ & $M$ & $S D$ & 1 & 2 & 3 & 4 & 5 & 6 & 7 & 8 \\
\hline 1.BMI & - & 21.89 & 3.18 & - & - & - & - & - & - & - & - \\
2.EMWSS-P & .97 & 35.58 & 10.28 & -.04 & - & - & - & - & - & - & - \\
3.SBS & .85 & 20.59 & 8.70 & .01 & $-.36^{* * *}$ & - & - & - & - & - & - \\
4.PSPS-BI & .95 & 77.99 & 23.04 & $.18^{* * *}$ & $-.32^{* * *}$ & $.36^{* * *}$ & - & - & - & - & - \\
5.RESTR_EDE-Q & .81 & 0.94 & 1.14 & $.21^{* * *}$ & $-.15^{* *}$ & $.15^{* * *}$ & $.40^{* * *}$ & - & - & - & - \\
6.EAT.C_EDE-Q & .80 & 0.65 & 0.96 & $.25^{* * *}$ & $-.27^{* * *}$ & $.28^{* * *}$ & $.54^{* * *}$ & $.59^{* * *}$ & - & - & - \\
7.WEI.C_EDE-Q & .84 & 1.61 & 1.39 & $.40^{* * *}$ & $-.22^{* * *}$ & $.24^{* * *}$ & $.64^{* * *}$ & $.59^{* * *}$ & $.74 * * *$ & - & - \\
8.SHA.C_EDE-Q & .93 & 1.82 & 1.53 & $.30^{* * *}$ & $-.31^{* * *}$ & $.30^{* * *}$ & $.70^{* * *}$ & $.59^{* * *}$ & $.75^{* * *}$ & $.90^{* * *}$ & - \\
9.EDE-Q & .95 & 1.33 & 1.16 & $.33^{* * *}$ & $-.28^{* * *}$ & $.28^{* * *}$ & $.68^{* * *}$ & $.75^{* * *}$ & $.85^{* * *}$ & $.94^{* * *}$ & $.96^{* * *}$ \\
\hline
\end{tabular}

Note $:$ BMI = Body Mass Index; EMWSS-P = Early Memories of Warmth and Safeness Scale - Peer version; SBS $=$ Submissive Behavior Scale; PSPS-BI $=$ Perfectionistic Self-Presentation Scale - Body Image; EDE-Q = Eating Disorder Examination Questionnaire (subscales and global Score).

$* * p<.010, * * * p<.001$.

\section{Path analysis}

The theoretical model was tested through a fully saturated initial model consisting of 23 parameters. This initial model explained 13\%, 19\% and 51\% of the SBS, PSPS-BI and EDE-Q's variances, respectively. However, some of the paths were not significant: the BMI's direct effect on $\operatorname{SBS}\left(b_{\mathrm{BMI}}=-.01 ; \mathrm{SE}_{\mathrm{b}}=.14 ; Z=-.08 ; p=\right.$ 
$.94)$, the SBS's direct effect on EDE-Q $\left(b_{\mathrm{EDE}-\mathrm{Q}}=.01 ; \mathrm{SE}_{\mathrm{b}}=.01 ; Z=.99 ; p=.32\right)$, and the covariance between BMI and EMWSS-P $\left(b=-1.16 ; \mathrm{SE}_{\mathrm{b}}=1.77 ; Z=-.66 ; p=.51\right)$. According to these results, these paths were eliminated and the model was readjusted.

The recalculated model explained 13\%, $19 \%$ and $51 \%$ of the SBS, PSPS-BI and EDE-Q's variances respectively, after controlling for BMI (Figure 1). All path coefficients were statistically significant, showing an excellent model fit $\left[\chi_{(3)}^{2}=1.41, p\right.$ $=.71, \mathrm{CMIN} / d f=.47 ; \mathrm{TLI}=1.02 ; \mathrm{CFI}=1.00 ; \mathrm{NFI}=1.00 ; \mathrm{RMSEA}=.00, p=.88,95 \%$ $\mathrm{CI}=.00$ to .07$]$.

Firstly, to what concerns EMWSS-P, results showed a direct effect on SBS $(\beta=$ $\left.-.36 ; b_{\text {EMwSS-P }}=-.31 ; \mathrm{SE}_{\mathrm{b}}=.04 ; Z=-7.20 ; p<.001\right)$ and, in turn, SBS presented a direct effect on PSPS-BI $\left(\beta=.28 ; b_{\mathrm{SBS}}=.74 ; \mathrm{SE}_{\mathrm{b}}=.14 ; Z=5.34 ; p<.001\right)$. Furthermore, EMWSS-P, results showed a total effect of -.31 on PSPS-BI, with a direct effect of $-.21\left(b_{\text {EMWSS-P }}=-.47 ; \mathrm{SE}_{\mathrm{b}}=.12 ; Z=-3.98 ; p<.001 ; \beta=-.21\right)$, and an indirect effect of -.10 mediated by SBS (95\% CI $=-.15$ to -.06). Also, EMWSS-P presented a total effect of -.27 on EDE-Q, with a direct effect of -.08 ( $b_{\text {EMwsS-P }}=-.01 ; \mathrm{SE}_{\mathrm{b}}=.00 ; Z$ $=-2.09 ; p<.05)$, and an indirect effect of $-.19(95 \% \mathrm{CI}=-.26$ to -.12$)$ mediated by both SBS and PSPS-BI. Finally, PSPS-BI presented a direct effect of .61 on EDE-Q $\left(b_{\text {PSPS-BI }}=.03 ; \mathrm{SE}_{\mathrm{b}}=.00 ; Z=15.07 ; p<.001\right)$.

Furthermore, BMI showed a direct effect on PSPS-BI $\left(\beta=.17 ; b_{\mathrm{BMI}}=1.20 ; \mathrm{SE}_{\mathrm{b}}\right.$ $=.35 ; Z=3.42 ; p<.001)$, and also a total effect of .33 on EDE-Q, with a direct effect of $.22\left(b_{\mathrm{BMI}}=.08 ; \mathrm{SE}_{\mathrm{b}}=.01 ; Z=5.81 ; p<.001\right)$, and an indirect effect of $.10(95 \% \mathrm{CI}=$ .04 to .16) mediated by PSPS-BI.

To sum up, the model accounted for 51\% of EDE-Q's variance, revealing that the impact of early positive memories with peers on eating psychopathology severity is partially mediated through defensive responses (submissive behaviors and perfectionistic self-presentation - body-image), when controlling for BMI. 


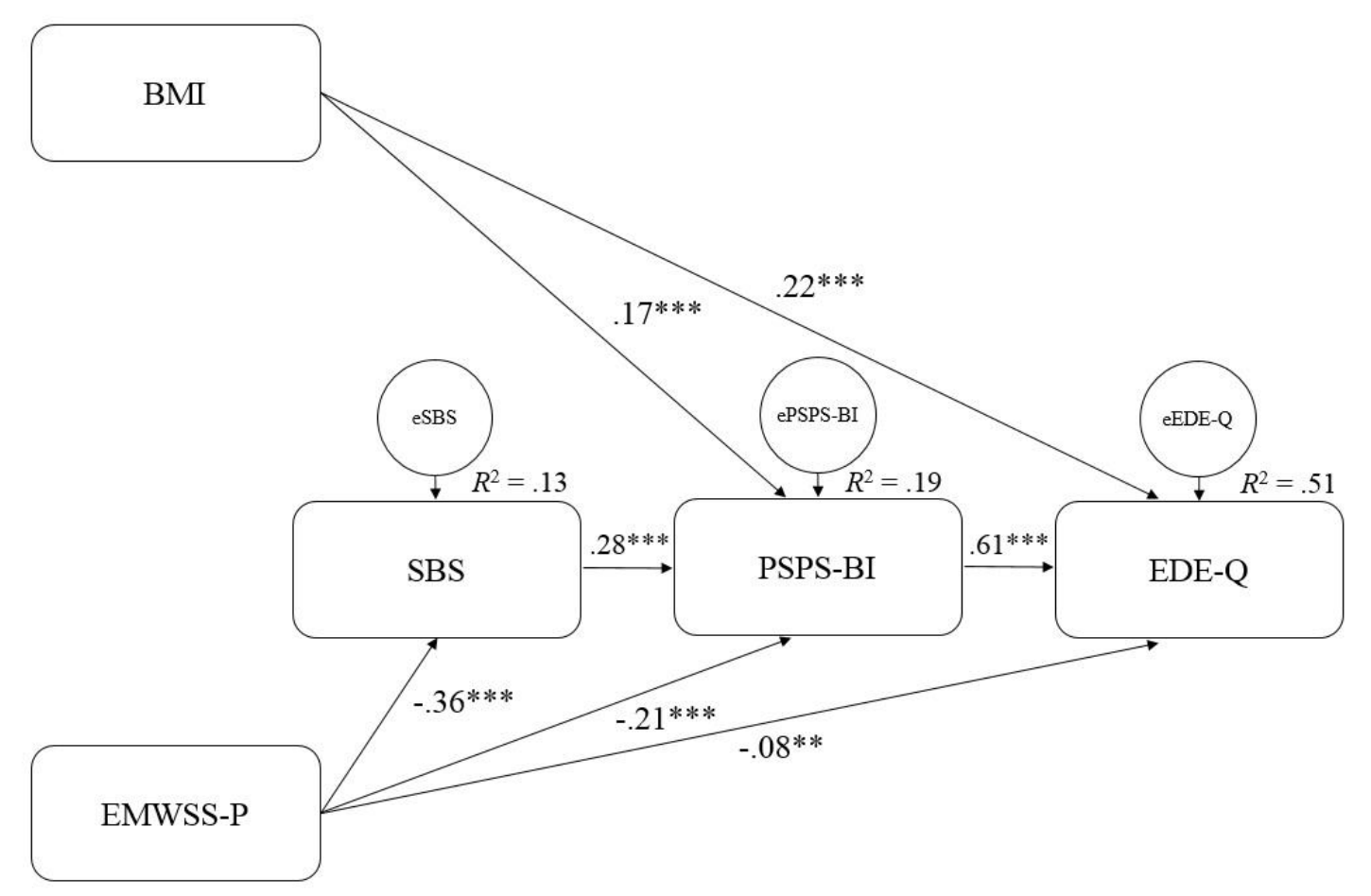

Figure 1. Final path model. Standardized path coefficients among variables are presented. $* * p<.01 ; * * * p<.001$.

\section{Discussion}

The present study intended to explore the relationship between early positive memories within the peer group and disordered eating attitudes and behaviors' severity, and also whether submissiveness and the need to present a perfect body image mediate this relationship. This novel approach to eating psychopathology was based on previous research (e.g. Gilbert et al., 2006; Richter et al., 2009; Sweetingham \& Waller, 2008) on the role of early affiliative memories and defensive responses on adult adjustment and vulnerability to psychopathology (e.g., Hewitt et al., 2003; Sloman et al., 1994). In this line, the proposed model hypothesized that the absence of early positive memories with peers would predict higher levels of eating psychopathology severity, through an increase of submissive behaviors and a higher tendency to engage in body image-related perfectionistic self-presentation, considered as possible defensive responses.

The model explained $51 \%$ of a global score of EDE-Q and corroborated our hypothesis, showing that submissive behaviors and perfectionistic self-presentation strategies focused on body image partially mediate the relationship between early affiliative memories with peers and eating psychopathology severity, when controlling for BMI. 
This is the first study that tested the link between early positive memories with peers, submissive behaviors, and the tendency to adopt a perfectionistic selfpresentation. Results showed a negative association between early positive memories with peers and submissive and body image-related perfectionistic self-presentation strategies. These findings suggest that the absence of warmth and safeness memories within the peer group may trigger feelings of inferiority and unattractiveness, and promote the adoption of defensive responses in order to assure acceptance by others.

Furthermore, our results are in line with previous literature which revealed that submissiveness is associated with higher levels of disordered eating (e.g., Katzman, 1985; Troop \& Treasure, 1997). Also, our findings seem to be in accordance with previous research (Ferreira, Duarte et al., 2015, manuscript submitted for publication; Ferreira, Trindade et al., 2015) by suggesting body-image related perfectionistic selfpresentation as a maladaptive strategy, which may be linked to the adoption of disordered eating attitudes and behaviors. Specifically, this study seems to extend previous knowledge since it revealed that perfectionistic self-presentation focused on body image acts as a mediator mechanism between submissiveness and eating psychopathology. In fact, our results seem to demonstrate that submissive behaviors directly explain higher levels of body image-related perfectionistic self-presentation. Moreover, although our findings revealed that submissiveness did not directly explained eating psychopathology, the tested model seems to demonstrate that this relation is fully explained by the increased perception of the need to present a perfect body image to others.

Furthermore, these results suggest that submissive and perfectionistic selfpresentation may act as maladaptive compensatory mechanisms used to cope with feelings of inferiority and a perceived loss of social status, which may emerge from memories with peers absent in warmth and safeness. Altogether, the current study suggests that submitting to others and striving to present a perfect body-image may impact on the tendency to adopt disordered eating attitudes and behaviors, when in the absence of early positive memories with peers.

These results should be interpreted considering some methodological limitations. Firstly, the cross-sectional nature of the data limits any causal inferences. In fact, this study explored a theoretical model and prospective studies are necessary in order to validate the nature and direction of the tested model. Secondly, considering the use of a non-clinical student sample, future research should replicate these findings in different 
samples, namely eating disorder samples. It should also be taken into account that the psychometric properties of EMWSS-P are not yet published, which may represent a limitation to the present study. Furthermore, it is important to note that the use of selfreport measures may compromise the generalization of the data, particularly self-report height and weight, as opposed to researchers weighing participants, may have led to a neglectful calculus of Body Mass Indexes. Finally, since eating psychopathology is a multi-determined complex phenomenon, other variables may be involved. However, the present model was designed and limited with the specific purpose of exploring the role of submissive and body image-related perfectionistic self-presentation defensive mechanisms on the impact of early positive memories with peers on eating psychopathology.

Notwithstanding some limitations, this is the first study that explored simultaneously the roles of submissive and perfectionistic self-presentation strategies on the adoption of disordered eating attitudes and behaviors. In fact, this study seems to highlight the harmful effects of defensive responses and mechanisms, used to cope with feelings of inferiority, on eating psychopathology. These findings seem to offer important investigational implications, suggesting also the relevance of targeting defensive behaviors on the development of mental health promotion programs among female students. 


\section{References}

Allan, S., \& Gilbert, P. (1995). A Social Comparison Rating Scale: Psychometric properties and relationship to psychopathology. Personality and Individual Differences, 19, 293-299. http://dx.doi.org/10.1016/0191-8869(95)00086-L

Allan, S., \& Gilbert, P. (1997). Submissive behavior and psychopathology. British Journal of Clinical Psychology, 36, 467-488. http://dx.doi.org/10.1111/j.20448260.1997.tb01255.x

Baldwin, M. W., \& Dandeneau, S. D. (2005). Understanding and modifying the relational schemas underlying insecurity. In M. W. Baldwin (Ed.), Interpersonal Cognition (pp. 33-61). New York, NY: Guilford press.

Cockell, S. J., Hewitt, P. L., Seal, B., Sherry, S., Goldner, E. M., Flett, G. L., \& Remick, R. A. (2002). Trait and self-presentational dimensions of perfectionism among women with anorexia nervosa. Cognitive Therapy and Research, 26, 745-758. http://dx.doi.org/10.1023/A:102123741636

Connan, F., Troop, N., Landau, S., Campbell, I. C., \& Treasure, J. (2007). Poor social comparison and the tendency to submissive behavior in anorexia nervosa. The International Journal of Eating Disorders, 40, 733-739. http://dx.doi.org/10.1002/eat.20427

Cunha, M., Matos, M., Faria, D., \& Zagalo, S. (2012). Shame memories and psychopathology in adolescence: The mediator effect of shame. International Journal of Psychology and Psychological Therapy, 12, 2.

Fairburn, C. G., \& Beglin, S. J. (1994). Assessment of eating disorders: Interview or self-report questionnaire? The International Journal of Eating Disorders, 4, 363-370.

Ferreira, C., Cunha, M., Marta-Simões, J., Duarte, C., Matos, M., \& Pinto-Gouveia, J. (2016). Early memories of warmth and safeness with peers scale: A new measure for the assessment of peer-related positive emotional memories. (Manuscript submitted for publication).

Ferreira, C., Duarte, C., Pinto-Gouveia, J., \& Lopes, C. (2015). The need to present a perfect body image and its impact on disordered eating. (Manuscript submitted for publication).

Ferreira, C., Trindade, I. A., \& Ornelas, L. (2015). Exploring drive for thinness as a perfectionistic strategy to escape from shame experiences. The Spanish Journal of Psychology, 18, e29. http://dx.doi.org/10.1017/sjp.2015.27

Freitas, P. (2011) Modelos de relação interna: Auto-criticismo e Auto-compaixão. Uma abordagem evolucionária compreensiva da sua natureza, função e relação com a psicopatologia [Internal relationship models: Self-criticism and self-compassion. An evolutionary approach to understand its nature, function and relationship with psychopathology]. (Unpublished master's thesis). Faculty of Psychology and Educational Sciences, University of Coimbra, Portugal.

Gatward, N. (2007). Anorexia nervosa: An evolutionary puzzle. European Eating Disorders Review, 15, 1-12. http://dx.doi.org/10.1002/erv.718

Gilbert, P. (1989). Human nature and suffering. Hove, UK: Lawrence Erlbaum Associates.

Gilbert, P. (1992). Depression: The evolution of powerlessness. Hove, UK: Lawrence Erlbaum Associates.

Gilbert, P. (1997). The evolution of social attractiveness and its role in shame, humiliation, guilt and therapy. British Journal of Medical Psychology, 70, 113147. http://dx.doi.org/10.1111/j.2044-8341.1997.tb01893.x 
Gilbert, P. (2000). Varieties of submissive behavior as forms of social defense: Evolution and psychopathology. In L. Sloman \& P. Gilbert, P. (Eds), Subordination: Evolution and mood disorders (pp. 3-45). New York, UK: Lawrence Erlbaum.

Gilbert, P. (2003). Evolution, social roles and the differences in shame and guilt. Social Research, 70, 1205-1230.

Gilbert, P. (2005). Social mentalities: A biopsychosocial and evolutionary reflection on social relationships. In M. W. Baldwin (Ed.), Interpersonal cognition (pp. 299335). New York, NY: Guilford Press.

Gilbert, P., \& Allan, S. (1994). Assertiveness, submissive behavior and social comparison. The British Journal of Clinical Psychology, 33, 295-306. http://dx.doi.org/10.1111/j.2044-8260.1994.tb01125.x

Gilbert, P., \& Allan, S. (1998). The role of defeat and entrapment (arrested flight) in depression: An exploration of an evolutionary view. Psychological Medicine, 28, 585-598. http://dx.doi.org/10.1017/S0033291798006710

Gilbert, P., Baldwin, M. W., Irons, C., Baccus, J. R., \& Palmer, M. (2006). Selfcriticism and self-warmth: An imagery study exploring their relation to depression. Journal of Cognitive Psychotherapy: An International Quarterly, 20, 183-200. http://dx.doi.org/10.1891/jcop.20.2.183

Gilbert, P., Price, J., \& Allan, S. (1995). Social comparison, social attractiveness and evolution: How might they be related? New Ideas in Psychology, 13, 149-165. http://dx.doi.org/10.1016/0732-118X(95)00002-X

Hewitt, P. L., Flett, G. L., \& Ediger, E. (1996). Perfectionism and depression: Longitudinal assessment of a specific vulnerability hypothesis. Journal of Abnormal Psychology, 105, 276-280. http://dx.doi.org/10.1037/0021$\underline{843 X .105 .2 .276}$

Hewitt, P. L., Flett, G. L., Sherry, S. B., Habke, M., Parkin, M., Lam, R. W., ... Stein, M. B. (2003). The interpersonal expression of perfection: Perfectionistic selfpresentation and psychological distress. Journal of Personality and Social Psychology, 84, 1303-1325. http://dx.doi.org/10.1037/0022-3514.84.6.1303

Irons, C., Gilbert, P., Baldwin, M.W., Baccus, J. R., \& Palmer, M. (2006). Parental recall, attachment relating and self-attacking/self-reassurance: Their relationship with depression. British Journal of Clinical Psychology, 45, 297-308. http://dx.doi.org/10.1348/014466505X68230

Katzman, M. A. (1985). Bulimia, binge eating and depression in college women: A study of coping strategies. (Unpublished doctoral disertation). Arizona State University, Arizona, AZ. ( $2^{\text {nd }}$ Ed.). New York, NY: Guilford Press.

Machado, P. P. P., Martins, C., Vaz, A. R., Conceição, E., Bastos, A. P., \& Gonçalves, S. (2014). Eating disorder examination questionnaire: Psychometric properties and norms for the Portuguese population. European Eating Disorders Review, 22, 448-453. http://dx.doi.org/10.1002/erv.2318

Matos, M., Ferreira, C., Duarte, C., \& Pinto-Gouveia, J. (2015). Eating disorders: When social ranking is shaped by early shame experiences. Psychology and Psychotherapy: Theory, Research and Practice. 88, 38-53. http://dx.doi.org/10.1111/papt.12027

Richter, A., Gilbert, P., \& McEwan, K. (2009). Development of an early memories of warmth and safeness scale and its relationship to psychopathology. Psychology and Psychotherapy: Theory, Research and Practice, 82, 171-184. http://dx.doi.org/10.1348/147608308X395213 
Sloman, L., Price, J., Gilbert, P., \& Gardner, R. (1994). Adaptive function of depression. Therapeutic interventions. American Journal of Psychotherapy, 48, $1-16$.

Sweetingham, R., \& Waller, G. (2008). Childhood experiences of being bullied and teased in the eating disorders. European Eating Disorders Review, 16, 401-407. http://dx.doi.org/10.1002/erv.839

Troop, N. A., Allan, S., Treasure, J. L., \& Katzman, M. (2003). Social comparison and submissive behaviour in eating disorder patients. Psychology and Psychotherapy, 76, 237-249. http://dx.doi.org/10.1348/147608303322362479

Troop, N. A., \& Treasure, J. L. (1997). Setting the scene for eating disorders II: Childhood helplessness and mastery. Psychological Medicine, 27, 531-538. http://dx.doi.org/10.1017/S0033291797005096 
